\title{
DOLOR DE DICTADURA, ANHELO DE REPÚBLICA. EL CASO DEL EMIGRANTE J. D. INFANTE Y EL REPUBLICANO
}

\author{
PAINING FOR THE DICTATORSHIP, LONGING FOR THE REPUBLIC. \\ THE CASE OF THE EMIGRANT J. D. INFANTE AND EL REPUBLICANO \\ Ángel Duarte Montserrat* \\ Universidad de Córdoba, España
}

\begin{abstract}
RESUMEN: Durante los años inmediatamente previos a la Segunda República española emigrantes como J. Daniel Infante propusieron, desde la República Argentina, una serie de criterios políticos a sus correligionarios españoles. La experiencia migratoria de larga duración le permitía conocer los complejos y ambivalentes efectos de las olas democratizadoras en los marcos estatales republicanos forjados por el liberalismo a mediados del siglo XIX. Desde la perspectiva de la historia cultural de la política este artículo aborda el análisis de las indicaciones y sugerencias, liberales y republicanas, democráticas y contenidas tanto en lo relativo a la participación de las multitudes como a la naturaleza de la agenda de reformas, que Infante propuso a sus correligionarios.
\end{abstract}

PALABRAS CLAVE: Republicanismo; emigración; democracia; liberalismo; España; Argentina.

ABSTACT: During the years immediately before the Second Spanish Republic, emigrants, such as J. Daniel Infante, proposed, from the Argentine Republic, a series of political criteria to their Spanish co-religionists. Infante's long-term migration experience allowed him to know the complex and ambivalent effects of the democratizing waves in the framework of Republican states erected by liberalism in the mid-19th century. From the perspective of the cultural history of politics, this article focuses on the analysis of democratic clues an suggestions, from liberal and republican basis, contained both in terms of the participation of the crowds and the nature of the reform agenda, which Infante proposed to his co-religionists.

KEYWORDS: Republicanism; Migration; democracy; liberalism; Spain; Argentina.

Nota del Editor: El monográfico del que forma parte este artículo fue aceptado por Historia Contemporánea con anterioridad a la incorporación de Ángel Duarte Montserrat al Consejo Editorial de la revista.

* Correspondencia a: Ángel Duarte Montserrat. Universidad de Córdoba, Facultad de Filosofía y Letras, Departamento de Historia Moderna, Contemporánea y de América, Plaza del Cardenal Salazar 3, 14071 Córdoba - aduarte@uco.es https://orcid.org/0000-0002-9929-6344

Cómo citar: Duarte Montserrat, Ángel (2020). «Dolor de dictadura, anhelo de república. El caso del emigrante J. D. Infante y El Republicano»; Historia Contemporánea, 63, 453-482. (https://doi.org/10.1387/hc.21094).

Recibido: 17 septiembre, 2019; aceptado: 12 diciembre, 2019.

ISSN 1130-2402 - eISSN 2340-0277 / (C) 2020 UPV/EHU

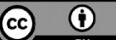

Esta obra está bajo una licencia

Creative Commons Atribución 4.0 Internacional 


\section{La emigración como viaje hacia la democracia}

La conversación política y cultural que, entre dos patrias, la de partida y la de acogida, sostiene el emigrante español en la Argentina, en el cambio de siglo XIX al XX y en los años de la República, la Guerra Civil y el franquismo, ha sido objeto de numerosas aproximaciones. Buena parte de ellas se centran en la gestión que sujetos y colectivos hacen de sus identidades étnicas. Identidades que operan en origen, en cubierta durante el viaje trasatlántico y en el quehacer cotidiano en el Río de la Plata ${ }^{1}$. Lo traído a cuestas y lo vivido incentiva dobles y/o múltiples patriotismos. La proliferación arranca del mezclarse lo interiorizado (local, regional, español) con lo argentino y, en la primera década del siglo XX, con un hispanoamericanismo reformista empeñado en regenerar España, posibilitar el registro transnacional y resintonizar desde la política a las ciencias sociales y jurídicas ${ }^{2}$. Son patriotismos que se complementan en círculos concéntricos o se decantan por la preferencia, la exclusividad y la oposición entre ellos. Que en América el paso de la compatibilidad al antagonismo se de en sintonía con lo que ocurre en la península, o que lo anticipe, no es una cuestión menor ${ }^{3}$. En ocasiones la distancia obra como un acelerador de lo que se va a dar en España; en otras aísla a sujetos y a colectivos.

La identidad nacional no es ni la única existente ni la sola cuya estabilidad se ve alterada por el hecho migratorio. Algunos españoles llevan a cuestas una condición republicana que marca su existencia en la Argentina y altera las percepciones en los retornos al primer hogar nacional. La hipótesis con la que abordamos este trabajo es la de que en culturas políticas como la republicana el cruce de referencias resulta de las coyunturas en cada uno de los Estados-nación tanto como de la circulación y singularidad de las historias personales. Y que, al cabo, son estas, las experiencias íntimas las que condicionan, en última instancia, la capacidad de ofrecer, o no, respuestas a las conveniencias de sus connacionales y, con ellos, a las de la democracia en España. Con los seres humanos viajan ideas y proyectos que mutan en función de las experiencias. En ciertos casos, no obstante, la condición republicana que viene de España lo hace con tal arraigo que ni siquiera quienes alcanzan a participar en la es-

\footnotetext{
${ }^{1}$ García Sebastiani y Núñez Seixas, 2020.

2 Cagiao, 2015; Moreno, 2010; Núñez Seixas, 2017 y 2019; Prado, 2006 y 2008; Zimmerman,1992 y 2015.

${ }^{3}$ Fernández, 2011.
} 
fera pública del país de acogida son capaces de impregnarse, en plenitud, de las formas y recursos de la cultura política argentina. Así, décadas más tarde, al pensar la patria de origen, lo que regurgita es un republicanismo de juventud y, por ello, de textura añeja.

En la colectividad el proceder republicano fue intermitente. La afirmación vale para el análisis del actuar que no en el del etéreo terreno del ser o, por especular en lo insondable, el del sentir(se). En la primera década del Novecientos hubo un episodio organizativo y en los años 1920 se dan otras iniciativas de activismo republicano ${ }^{4}$. Entre uno y otro momento se acoge a los líderes que toman el relevo a los del Ochocientos y se atiende a las prédicas profesorales de Adolfo Posada o Rafael Altamira ${ }^{5}$ Todo ello es escaso y discontinuo. No obstante, es significativo para analizar la circulación de ideas y la redefinición de las mismas por causa del cúmulo de situaciones que, en el segundo momento cronológico, el de los años veinte, alteran de raíz las condiciones del mundo de antes de la Gran Guerra: la conflagración en lo que tiene de reconsideración del papel del estado en la regulación social, la alteración de los mercados, la revolución bolchevique, la emergencia de los fascismos y el recurso a dictaduras militares en respuesta a las tensiones asociadas al tránsito del universo liberal a una democracia de masas acuciada por exigencias de representación y equidad.

El momento, a un lado y otro del Atlántico, es, pues, «un periodo de ensayos desigualmente exitosos de intervención del Estado en la sociedad civil». Ensayos que, diseñados, desde el poder o en la oposición, por elementos afines a la democracia liberal con inequívoca vocación reformista, «acabaron haciendo crisis» ${ }^{6}$. En el caso que nos ocupa nos enfrentamos a una condición liberal republicana, la de Julián Daniel Infante ${ }^{7}$, que afirma que el valor primero de la libertad privada no está reñido con el culto a la virtud cívica y con la probidad nacional. Dicha opinión se mantiene en medio de los flujos y reflujos que identifican a las oleadas democratizado$\operatorname{ras}^{8}$. La tesis se sostiene en España, claro está, pero también en América

${ }^{4}$ Duarte, 1993; Ortuño, 2011 y 2018.

5 Castro, 2015.

6 García Sebastiani, 2010,p. 7.

7 Pasquali, 1996 y Duarte, 2010.

8 Markoff, 2018; Smith, 2005, p. 12: «as the historical record indicates, democratization is by no means an inexorable process: democracies can rise, fall and return». Romero, 2004 y 2014. 
Latina. Las repúblicas americanas, todas ellas, constituían, para los españoles atentos, un «magno laboratorio político» ${ }^{9}$.

El recorrido de Infante recuerda que para que haya republicanos españoles en la Argentina no hay que esperar a los años 1930. Republicanos españoles los hay en Buenos Aires, en el litoral y en el interior desde que los hay en España. Y ello es así desde que ciertos actores de la revolución liberal constatan las limitaciones a los procesos participativos y las exclusiones padecidas por su condición de demócratas beligerantes. En la Argentina recalan republicanos españoles antes y después de la clausura del Sexenio Democrático y, con él, el del tiempo de la República de 1873. El demócrata implicado en los avatares del Sexenio se encuentra en la Restauración vetado al beneficio del favor y la influencia; bloqueado en sus expectativas más que perseguido - a no ser que se haya sumado a alguna de las muchas pero febles insurrecciones cívico-militares progresistas ${ }^{10}$.

En América ese demócrata tiene la oportunidad, tras un viaje sanador, de vivir en república. Una república liberal y aluvial, la de finales de la década de 1880 y principios de los noventa, asociada a la construcción de un Estado y a la forja de una nación joven, enérgica y orientada al futuro. Una república que le convoca ${ }^{11}$. Ese republicano parte de la premisa que va a un mundo en el que, desde 1853/1860, rigen constituciones guardianas de la soberanía nacional, la participación ciudadana y la representatividad. Viajero audaz sabe del dinamismo de la participación, aunque apenas sabe de la revisión de las «fronteras del campo de acción del Estado que definen la intersección entre lo público y lo privado», o del agotamiento, o no, de la funcionalidad de la economía política y las limitaciones del papel estatal en este campo. Incluso, si llega antes de la presidencia de Julio A. Roca, lejos está de preguntarse si dicha república ha alcanzado la plenitud del control territorial ${ }^{12}$.

Ese español cree, en suma, que llega a un país moderno que participa de la cartografía del progreso y la democracia. Ese republicano vive las crisis y dificultades que acaecen entre siglos y las entiende como inherentes a la emergencia de la sociedad de masas; pero, en la Argentina, contando con la ventaja de ser un país abierto al despliegue de la democracia liberal. País, por decirlo con Blasco Ibáñez, «de rápidas mutaciones y

\footnotetext{
9 Jaén, 1934, p. 13.

${ }^{10}$ Higueras, 2016, pp. 327-376; Bachero, 2017.

11 Romero, J.L., 1980, pp. 7-8; Bertoni, 2001, pp. 121-155.

12 Guerra, 1994, p. 40; Sábato, 1998; Zimmerman, 2020 (en prensa).
} 
vertiginosos progresos», país «que ofrece libertad a todos los hombres y amplios medios para la conquista del bienestar» ${ }^{13}$. Una nación en la que, sensu contrario, los llamados, equívocos y vacilantes, de las autoridades nacionales a la naturalización y al ejercicio del sufragio no siempre obtienen respuesta positiva ${ }^{14}$.

En el doble terreno de las expectativas profesionales y políticas se dan, por parte de las elites republicanas españolas, éxitos y fracasos y la constatación, entrado el siglo XX, de lo efímero de las olas democratizadoras, de los riesgos demagógicos inscriptos en las mismas y de la posibilidad de que, incluso en república, estas ondas sean sucedidas por otras autoritarias ${ }^{15}$.

La migración española a la Argentina es, entre 1880 y 1930, masiva. Dos millones de españoles cruzan el Atlántico y cerca de un $60 \%$ de ellos se establecen definitivamente en el país de acogida. Constituyen, los españoles, el segundo grupo tras los italianos en el arribo a la república austral. De la instalación del grueso de ellos, acaso con la excepción de los vascos, en el medio urbano y de su preferencia por centrar sus actividades profesionales en el sector terciario se ha escrito con profusión. Rosario, la ciudad en la que se pergeña la obra que centra las páginas finales de este texto es, por su parte, la ciudad que concentra a un mayor número de esos emigrantes que optan por ubicarse en la provincia de Santa $\mathrm{Fe}^{16}$.

Lo que pretendemos en esta aportación es, tras revisar el poso previo, centrarnos en la última de las aportaciones del Infante rosarino, aquella que a mediados de la década de 1920, en una coyuntura resuelta en Rosario mediante un proceso de reforma constitucional ${ }^{17}$ que, con toda seguridad, a Infante le relega a una condición de observador, le lleva a reconsiderar dos decisiones vitales tomadas poco antes con carácter irreversible: la renuncia a intervenir en el debate doctrinal acerca de qué cosa era vivir en república y más concretamente en una democracia liberal y el desentenderse de España, dejándola, en tanto que hombre de su tiempo, por imposible. La doble palinodia tiene como causa tanto el cierre del ciclo constituyente santafesino como la llegada y rápida consolidación de la

13 Blasco Ibáñez, 1910, p. 90; Cortés, 1979; Moya, 1998, pp. 205-276.

14 García Sebastiani, 2013; Devoto, 2003, pp. 323-327. Reflexiones de López de Gomara a propósito de ello en Sepúlveda, 2005, pp. 382-384.

15 García Sebastiani, 2013, p. 470.

16 Miragaya y Solanes, 1934; Núñez Seixas, 2013, p. 857.

17 Mauro, 2007. 
dictadura militar de Miguel Primo de Rivera, en 1923. El contexto procura la posibilidad de la convergencia y el intercambio de elementos de análisis político e ideológico entre sectores de las élites intelectuales a ambos lados del Atlántico ${ }^{18}$. El patriotismo y la concepción liberal de la vida renuevan al republicanismo. Lo hacen en la península y en América, y en biografías como la de Infante llevan a retomar un quehacer llevado a cabo desde su llegada a la Argentina a finales de la década de 1880. En los años veinte, con El Republicano, empresa periodística e imprecisamente organizativa, procura un doble objetivo: relanzar Rosario como foco del republicanismo hispano y aportar nociones para el futuro de España. Nociones intrínsecas a la experiencia migratoria y a los usos e ideas socioeconómicas, políticas y culturales aprehendidas en la Argentina anterior a $1930^{19}$.

\section{Escribir sobre España...}

El hombre que entre 1927 y 1929 forja un corpus de propuestas sobre el sentido liberador que la república tiene para España cuenta con un pasado político, español y argentino ${ }^{20}$. En 1889 , y debido al efecto en las autoridades de una intervención suya en la palentina villa de Torquemada, decide emigrar. En el acto en cuestión evoca el levantamiento que tres años antes protagoniza el brigadier Manuel Villacampa. Infante, maestro, periodista ocasional y abogado, tiene 26 años y forma parte de las huestes que siguen, tras la Primera República, a Manuel Ruiz Zorrilla. Infante aprovecha el mitin para hacer una serie de llamados «prácticos» a la acción conspirativa. El fervor desplegado le hace temer por su seguridad en España ${ }^{21}$. Es, Infante, uno de esos castellanos a la manera de Ricardo Macías Picavea, que por entonces participa en la democracia progresista, asocia el triunfo de la libertad a un proceso de reforma que, nutrido por la educación, garantice la igualdad de oportunidades; son, uno y otro, castellanos que creen también en la disciplina social y el reconocimiento de la jerarquía asociada al mérito ${ }^{22}$.

\footnotetext{
18 Niño, 1993, p. 29; Sepúlveda, 2005.

19 Halperin Donghi, 2013.

20 Pasquali, 1996; Duarte, 2010.

${ }^{21}$ Infante, 1893 , pp. 52-53.

22 Serrano Blanco, 1999; García Sebastiani, 2008.
} 
Tras pasar por Lisboa, Infante viaja a Argentina y, concretamente, a una Rosario, centro de exportación cerealista ${ }^{23}$. Llega a una ciudad a la que se conocerá como la «Barcelona del Río de la Plata» por la alta concentración de inmigrantes y por el peso de los elementos anarquistas entre ellos. Pero no es menos exacto que arriba a una región argentina en la que, por parte de las élites liberales, se discutía, con grandes dosis de contención, el alcance de un segundo umbral secularizador y laicista ${ }^{24}$. Un dato en absoluto menor para entender el acomodo y la contención de los puntos de vistas infantinianos - alguien que no desea en modo alguno convertirse en un enemigo interior - en este punto. Infante viaja atendiendo a la propuesta de un poblador, banquero y, en particular, empresario ferroviario de éxito en la ciudad, la provincia y en países del entorno: Carlos Casado del Alisal ${ }^{25}$. El paisanaje que comparten, la condición de castellanos viejos que no precisa de mayores sintonías ideológicas, y la laudatio que Infante dedica en un homenaje al pintor historicista José Casado, hermano de Carlos, forjan la estima personal que induce al empresario a llamar a su lado a Infante. Un emigrante que ha triunfado como empresario y poblador precisa a su lado de talento del que se pueda fiar. Infante cuenta, en los primeros pasos en Argentina, con líderes de otra red que aún no siendo la que le ha invitado le acogerá como suele hacerlo con las personalidades de su perfil ${ }^{26}$. Red que abarca el conjunto del país y que le facilita contactos, le avala en su andadura y acaba peleándose con él. Red, en fin, que cuenta en la presidencia de asociaciones y en la dirección de periódicos con nombres que, no habiendo llegado mucho antes, se han convertido en claves de bóveda de una corriente de republicanos que, de tanto en vez, se reconocen como tales en el seno de la colectividad. Gentes tan diversas como Justo López de Gomara, sustituto al frente de El Correo Español ${ }^{27}$ del presbítero revolucionario y aciago duelista Enrique Romero Jiménez, o Carlos Malagarriga y Rafael Calzada ${ }^{28}$. Son individuos que conforman una trama de amistades tornadizas que, a pesar de los choques ideológicos

\footnotetext{
${ }^{23}$ Gallo, 1984.

24 Mauro, 2014.

25 Blasco, 1910, p. 563; Dalla Corte, 2009; Martirén, 2014. Enemigo interior en Sierra, 2014.

26 Moya, 1998, pp. 272-330; Núñez Seixas, 2016, pp. 136-154; Devoto, 2006, pp. 9-14; Blanco, 2008.

27 Garabedian, 2017; García Sebastiani, 2004.

28 Para el liderazgo de Calzada, Da Orden, 1999 y Duarte, 1998. Influencia republicana en García Sebastiani, 2006.
} 
o de carácter, operan como un segundo sostén sobre el que edificar la incidencia de Infante. Lo que para otros lo constituyen las sociedades regionalistas y nacionalistas subestatales, para Infante lo será el patriotismo del mundo republicano ${ }^{29}$.

Ya en los primeros años 1890 Infante se construye una posición. Lo hace en un múltiple plano. Primero, como administrador y abogado de la «fortuna inmensa» de Casado hasta la muerte del mismo en 1899. La tarea le convierte en otro exitoso hombre de negocios. Su rol en el comercio y la manufactura, así como la labor pobladora, determinan su relevancia como figura pública en un territorio en expansión que precisa de articulación en todos los planos. Infante pasa a ser una figura clave en la cohesión de la colectividad y en la intermediación de la misma con las dirigencias argentinas. No es extraño que, a raíz de la revolución de 1893, pase a hacerse presente, políticamente hablando, en la vida rosarina. Junto a todo ello, Infante, dedica esfuerzos a reflexionar sobre la república en España.

Fue llegar a Rosario y ponerse a escribir de España. En 1889 Infante redacta un folleto que dedica «a los republicanos de Torquemada»: Estudiemos política. El texto es una vindicación de la Política. El ser humano, para alcanzar la plenitud, debe dedicarse a ella. El terreno ideal para el despliegue de ese compromiso cívico con el progreso y la libertad es, en España como en todas partes, el de la República. Una república que asiente al ciudadano en la esfera pública y asegure la libertad, la justicia, el progreso y la solidaridad ${ }^{30}$. En un trabajo posterior Infante precisa qué tipo de república: unitaria. Sabedor, y partícipe, de la competencia feroz entre federales y unitarios asegura, en Unitarismo y federación, que es una confusión interesada la consideración de federal como sinónimo de avanzado y de unitario como autoritario y conservador ${ }^{31}$. Lo que define a la república unitaria es la existencia de un único sujeto de soberanía. Los cuerpos intermedios que mediante pactos recomponen el cuerpo político de abajo a arriba falsean, dice, la expresión de la voluntad ciudadana, convierten en forasteros a compatriotas y aumentan la complejidad administrativa y la arbitrariedad. En España el estado federal multiplicaría las lenguas oficiales. Todo, en suma, excepto el personal preparado para la gestión pública. La ineficacia y el narcisismo de las pequeñas diferencias

\footnotetext{
29 Núñez Seixas, 2019, pp. 705 y ss.

30 Infante, 1893, pp. 6-50.

31 Infante, 1894, pp. 11-13.
} 
conllevaría, a medio plazo, la amenaza de separación. Solo la nación unitaria avala los derechos individuales y garantiza el bien común ${ }^{32}$.

El nacionalismo de Infante es castellanista y glotopolítico ${ }^{33}$; pero no es un patriotismo ciego. En tiempos de la guerra hispano-cubana-norteamericana, en pleno paroxismo emocional, Infante choca con la Asociación Patriótica Española ${ }^{34}$. La guerra está perdida y lo patriótico no es regodearse en el lamento o en la «nostalgia cubana» sino mirar al mañana. Lo que debe hacer la sociedad española es $s u$ revolución ${ }^{35}$. En 1899, aprovechando el deceso de Casado viaja a España. En rigor, y entre los emigrantes exitosos y los partícipes de la condición de miembros de las élites españolas no es extraño el viaje, más o menos episódico, de visita a la tierra de los padres y de la infancia. Lo que no siempre contribuye, como vemos, a reforzar recuerdos positivos, por nostálgicos y melancólicos. Allí se encuentra, Infante y por contraste con Rosario, con un paisanaje macilento y enclenque, sometido y condenado a la miseria. En ese momento no se le ocurre otra que ofrecer como salida la emigración. La consigna revolucionaria es inaudita: « A fuera, a fuera los más bravos! ¡A vencer o a morir de una vez...!». En 1908, en el opúsculo en que da cuenta de las notas de ese viaje, Infante sostiene su cosmovisión liberal-republicana y cosmopolita. La libertad de movimientos debe ser absoluta. La liquidación de barreras no implica solo a las personas, también a mercaderías y capitales. España debe adoptar el librecambio y liquidar las trincheras exteriores (los aranceles) y las interiores (los fielatos y las tasas que gravan los productos de consumo). En momentos en que proliferan, en respuesta a la crisis final del Imperio, particularismos nacionalistas, Infante apuesta por un cosmopolitismo con raíces autobiográficas: la primera libertad del ser humano es la de moverse «por toda la superficie de la Tierra y en el lugar paraje de ella que más nos acomodase» ${ }^{36}$.

La de moverse no es la única restricción a la autonomía del individuo que hay que liquidar. En liberal hay que suprimir la conscripción obliga-

32 Infante, 1894, pp. 18-37, 40-85 y 99. En el ejemplar de la Biblioteca Nacional de España consta el propietario original del mismo: «Francisco Pi y Margall. Abogado. Madrid».

33 Núñez Seixas, 2017,p. 413.

34 Romero, A.L., 2007 y Fernández, 1987.

35 Núñez Seixas, 2017, pp. 409-410; Infante, 1908.

36 Infante, 1908, pp. 3-7. Ese «¡A salir!» intentaba ser contrarrestado sin gran eficacia, Sepúlveda, 2005, pp. 366-367. 
toria, liberalizar la posesión y uso de armas, legalizar el juego o desregular la caza. ${ }^{37} \mathrm{Su}$ liberalismo se completa con una vocación reformista que, inevitablemente y esa es una paradoja que no es privativa de Infante, debía estar ligada al Estado. Como insistirá en la década de 1920, Infante anuncia que su horizonte es el de una sociedad de pequeños propietarios. Es por ello que propone un sistema crediticio que «habilit[e] a los laboriosos» y una tributación progresiva que «no exigiese nada de quien tuviese que renunciar al ahorro». Infante asume una concepción iusnaturalista de la propiedad de la tierra, la crítica de los latifundios y la partición y/o la agrupación familiar de parcelas. Por el momento, dado que eso solo daría frutos a medio plazo, debería implementarse una política de obras públicas y liberalizar, en su totalidad, el subsuelo español. A las empresas mineras extranjeras habría que asegurarles, incluso constitucionalmente, la seguridad de sus inversiones ${ }^{38}$.

Infante construye su visión del mundo y de las necesidades de España usando materiales procedentes, entre otros, del liberalismo y del positivismo, del reformismo social y, llegado el caso, de las filosofías orientales. La lógica última se halla, en cualquier caso y ya a esas alturas, sostenida sobre la noción de que la felicidad de las naciones radica en la felicidad, o infelicidad, de los individuos que las forman y que el objetivo de la política estriba en que los individuos vivan una «vida tranquila, desahogada y satisfecha» ${ }^{39}$; sin apuros, intranquilidades o penurias. Hay un canto a la acción política y al compromiso cívico con el destino de la patria mediante, desde la garantía de la solidez del espacio privado, la participación en la toma de decisiones que afectan al común y la vigilancia para con los poderosos que se arrogan funciones que no les corresponden.

\section{... y actuar (y seguir pensando) en Rosario}

El republicano no solo escribe y teoriza. Ese aspecto es importante pero no excusa el actuar. En Rosario, Infante tiene, tras la Revolución de 1893, un escenario propicio. El radicalismo santafesino y la democracia

37 Infante, 1908, pp. 25-27.

${ }^{38}$ Infante sostiene, lejos del canon regeneracionista, que «Minas y mares son nuestra dote, no la tierra, que es de lo peor, aunque un falso patriotismo quiera convencernos de lo contrario», Infante, 1908, pp. 14-17. Sincretismo en Pasquali, 1996, pp. 37-47.

39 Infante, 1894, pp. 3-4. 
progresista son espacios permeables y plurales, abiertos a la incorporación de actores como Infante ${ }^{40}$. Además, opera en la ciudad esa otra trama transnacional que permite, a un lado y otro del Atlántico, la presencia (discreta) en la esfera pública: la masonería. Los inicios no fueron fáciles. Tras alguna decepción, toma parte en 1908 en la fundación de la Liga del Sur, presidida por Lisandro de la Torre ${ }^{41}$. Por entonces ya se ha naturalizado argentino. A caballo del liguismo y, sin solución de continuidad, desde 1912, del radicalismo, Infante se desboca en los actos públicos; sin renunciar ni un ápice a su liberalismo democrático puede presentarse, si enfrente se encuentra con una voz obrera pidiendo concreciones, como socialista argumentando que eliminar las tributaciones sobre el trabajo y el consumo beneficia al proletariado y prometiendo su mediación en los conflictos entre propiedad y trabajo.

En el año de 1912, el de la Ley Sáenz Peña, el del paso de la república posible (instituciones fuertes, amplias libertades, pocos ciudadanos) a la república verdadera, o si se prefiere de la república oligárquica a la democracia como el deber de la hora, Infante llega, gracias a la propuesta del primer gobierno radical de Santa Fe (Manuel J. Menchaca y Ricardo Caballero) a la Intendencia rosarina ${ }^{42}$. El episodio, breve y convulso, del 20 de noviembre de 1912 al 10 de abril de 1913, afianzará su perfil reformista y su predisposición mediadora en favor del mundo del trabajo. Ello es así hasta tal punto que podrá presentársele como un intendente socialista ${ }^{43}$. Cosa que no será, aunque nos remite al papel y a las prácticas relacionales de radicalismo y mundo obrero, así como nos permite, como ocurre a menudo con las confusiones, afinar la comprensión del liberalismo social, democrático y redistributivo de Infante ${ }^{44}$.

Infante media para la liberación de detenidos a raíz de la huelga de colonos iniciada con el Grito de Alcorta, toma parte en las comisiones creadas para explicar los porqués del conflicto, elabora informes de denuncia del sistema de arrendamientos y anima a la organización de sus connacio-

40 Bonaudo, 1996 y 2005.

41 Pasquali, 1996, pp. 51-53.

42 Castro, 2012; Halperin Donghi, 2015, pp. 19-65. Para «the most grand and noblespectacle of democracy», en Santa Fe, a raíz de la reforma electoral, véase cita del conservador Ramón J. Cárcano en Horowitz, 2008, ebook p.9.

43 Videla y Zanella, 2004; Sánchez, 2005, pp. 91-102; Miragaya y Solanes, 1934, p. 163 .

44 Desmentido de los socialistas en La Capital, Rosario, 23 de diciembre de 1912; El socialismo y el intendente. 
nales o de otros inmigrantes. En la ciudad, junto a las reformas urbanísticas y la apertura de nuevos viales, impulsa la creación de barrios de viviendas obreras, media en huelgas no exentas de pasión y preside sepelios de obreros víctimas de la violencia. En suma, Infante no hace otra cosa en Rosario, como Caballero (con quien mantiene lazos estrechos), en el conjunto de la provincia, que el tipo de política gremial que se traslada al ámbito nacional con el primer gobierno de Hipólito Yrigoyen ${ }^{45}$.

El episodio como intendente no agota la presencia pública ni la vocación política argentina de un Infante abanderado de las luchas progresistas, defensor de los derechos de sus compatriotas - es decir, de los españoles tanto como de los argentinos-, y «hombre de consejo, alguien a quien la edad había aportado sosiego y clarividencia y que contribuía a orientar a quien a él se acercaba. Una suerte de patriarca, aureolado por su condición docente» ${ }^{46}$. Este último dominio no tiene una trascendencia menor. Inicia su labor pedagógica impartiendo Historia y de Filosofía en el Colegio Nacional número 1 para acabar ejerciendo, precisamente en los años en los que la reforma universitaria deviene uno de los campos de batalla centrales, como catedrático de Historia del Comercio, en la Facultad de Ciencias Económicas de la Universidad del Litoral.

En 1916 Infante publica el ensayo Insinuaciones. Ahí sistematiza, en detalle, lo que ha dicho de la enseñanza, la pedagogía y el magisterio. La atención que presta a la educación tiene que ver, ahora para la Argentina y en la segunda mitad de la década de los veinte para España, con el recurrente problema de la formación de una ciudadanía consciente y autónoma, de la responsabilidad de los poderes públicos en este ámbito y de la importancia trascendental que todo ello tiene en las posibilidades de establecimiento, a partir del reconocimiento explícito al esfuerzo y al mérito. de una democracia representativa, liberal, eficaz y reformista ${ }^{47}$.

En Insinuaciones, Infante introduce un argumento complementario - relativo a la historia - que tiene importancia para sus propuestas posteriores para España. El argumento nace del diálogo con Ricardo Caballero acerca de la relectura del ayer y los usos políticos de presente. La lectura criollista del pasado argentino, que como otros hace Caballero, genera interés en Infante. Caballero no recurre a estereotipos xenófobos. Al contra-

45 Karush, 1999; Rock, 1997, pp. 108 y ss; Horowitz, 2008; Sánchez, 2005, pp. 95-96; Pasquali, 1996, pp. 69-89 y 138-142.

46 Duarte, 2010, p. 76.

47 Infante, 1916, pp. 19-20 y 24-25. 
rio, reclama a los trabajadores venidos de fuera, y a su prole, que se identifiquen con el pasado criollo, se sientan pueblo argentino y hagan de esa identidad, y frente a las oligarquías vendepatrias, su propio proyecto de emancipación. El federalismo, que repele a Infante, es un punto de fricción; en cambio, como Caballero, Infante asume la tradición laicista y positivista como marco filosófico ${ }^{48}$. Español, argentino y latino, el terreno de encuentro de Infante y Caballero, en un contexto presidido por la proliferación de esquemas binario latinidad vs. germanidad o latinidad versus anglosajonismo, pasaría por considerar la primera categoría como análoga a civilización, racionalidad y cultura; frente a una segunda asociada a brutalidad, ausencia de escrúpulos y de legado cultural y moral. Sólo un presidente no latino podía exclamar «América para los americanos». Para Infante, en cambio, lo que proclamaría una autoridad, latina sería un «América para la Humanidad»49.

Tan enfrascado anda Infante con sus batallas rosarinas que España le queda lejos. Muy lejos. En 1920, Infante publica ¡iPor España!! La obra tiene no poco de carta con la que dar a conocer a su hijo sus raíces nacionales. El tono, alejado del título, es displicente. El régimen de la Restauración ha sobrevivido a las crisis de 1917 y 1919 porque España es un yermo atrasado e inercial ante el que solo cabe una declaración formal de ruptura $^{50}$. Cuando el vínculo con España aparenta ser un vago (y mal) recuerdo, tiene lugar la catarsis.

\section{La españolidad republicana en la desgracia...}

El 11 de septiembre de 1923 un golpe de estado protagonizado por el capitán general Miguel Primo de Rivera da paso a un Directorio militar. La Monarquía liberal y constitucional queda aparcada. El autoritarismo, en España como en otros rincones de Europa, o como en la Argentina de 1930, hace aparición aspirando a neutralizar las tensiones derivadas de la emergencia de la sociedad de masas, del protagonismo del pueblo y, de los efectos deletéreos de las presiones democráticas para con el orden liberal.

\footnotetext{
48 Zanella en Videla y Zanella, 2004, pp. 69-89.

49 Infante, 1916, pp. 56-57.

${ }^{50}$ Infante, 1920.
} 
Ante ese escenario Infante hace lo que otros republicanos en la reserva: retomar el combate ${ }^{51}$. Activa el Centro Republicano Español, controlado por los partidarios de Rodrigo Soriano, y edita El Republicano. El por qué se explicita en 1927: «La situación de España no puede ser indiferente para quien tenga sangre española en las venas, ni para quien ame la Libertad y la Igualdad». Los lazos no se han roto. El combate por la República los reverdece. Habrá que pelear con las directivas de clubes, patronatos, hospitales o mutuas españolas que han bendecido, con su silencio o abiertamente, la ruptura con la constitución de 1876. Y habrá que enfrentar a un embajador, Ramiro de Maeztu, que en 1928 evidencia, junto a la Exposición Iberoamericana de Sevilla en 1929 para la que Infante reclamará el vacío de las repúblicas americanas, la capacidad del hispanoamericanismo autoritario ${ }^{52}$. Hacerse presente en la esfera pública se convierte en una urgencia moral asociada a la dignidad nacional ${ }^{53}$. La renuncia a intervenir consiente con la tiranía y deja el campo libre a la impudicia y la arbitrariedad ${ }^{54}$, cede frente al atropello y la negación de todo régimen de ley. Infante siente de nuevo el prurito de la política, a pesar de que, a esas alturas de la vida, hubiese ocupaciones infinitamente más agradables.

Para el combate Infante retrotrae la tradición democrática, «milenaria», a Alarico y la libertad del municipio, pasa por comunidades y germanías y llega a su agostamiento a manos de monarquías irresponsables y extranjeras ${ }^{55}$. Infante despliega las obligadas antinomias monarquía/república y suscribe la tesis de Gumersindo de Azcárate, ya formulada en 1877, de la incompatibilidad de la monarquía doctrinaria con el principio de Self-governement. A Azcárate y a los hombres de su generación, que no a Infante, les marcó la incógnita de si la monarquía sería capaz de abrirse a la experiencia representativa ${ }^{56}$. La Dictadura disuelve la duda. La monarquía es dictadura. No solo la democracia sino, lo que resulta determinante en Infante, la democratización es

51 Blasco, 1924 y 1943.

52 El Republicano, 1932, p. 3; Delgado, 2003; Niño, 1993, pp. 47-48. Llamado al boicot a las embajadas en el Día de la Raza y a la Exposición sevillana en nombre de la solidaridad de liberales y demócratas frente a la tiranía, El Republicano, p. 66.

53 El Republicano, p. 4 y 62.

54 El Republicano, p. 32.

55 El Republicano, pp. 10 y ss.

56 Azcárate, 1931,p. 2; El Republicano, pp. 51 y 76-77. 
imposible en monarquía. El correlato es que la república deja de asimilarse a guerra civil y $\operatorname{caos}^{57}$. Desde ese punto de partida, teniendo en cuenta lo vivido en la Argentina, aceptando la irreversibilidad de las novedades políticas de la centuria y la singularidad de lo español, Infante lanza, durante meses, una serie de propuestas para España. No hay que esperar a la conquista del poder para concretar «qué hacer», cómo obrar en el solar vacío que quedará tras el uso de la piqueta y el derrumbe de lo existente.

No se trata, sin embargo, de trabar programas concretos. Ello atemorizaría a los indecisos y daría paso a desistimientos. Hay que esperar al cambio de régimen para dejar que, como suelen, los republicanos se «pele[e]n encarnizadamente». Lo que pide la hora es que todo español de bien intervenga de algún modo «en la agitación que, por España libre [un sintagma con recorrido posterior en la posguerra civil y mundial], está emprendida... ${ }^{58}$. Existe para el aplazamiento de las precisiones una razón adicional: la dictadura hace que proliferen los republicanos nuevos. Estos han de tener un papel decisivo en la determinación de los rasgos institucionales - república unitaria o federal, presidencialista o parlamentaria-, de los liderazgos y de los programas asociados al porvenir republicano ${ }^{59}$. Fijar las características de lo que debe ser una república para España resulta, en estas condiciones, especulativo. Hay, entiende Infante, una minoría republicana que preserva una memoria y una cultura secular. Pero son pocos frente a los que se suman gracias a «la imbécil perversidad regia» ${ }^{60}$. Lo que propone a los republicanos nuevos y a los, por el momento, «no republicanos», de manera más imperativa de lo que se presupone dada la circunstancia descrita, es una república que se nutra de los veneros del radicalismo progresista, de las experiencias de gestión e intervención en la Argentina y de una lectura liberal optimista de la vida social en un tiempo en que la misma parecía superada.

57 El Republicano, pp. 86-87.

58 El Republicano, p. 60: «Es el que intervengáis de algún modo en la agitación que, por España libre, está emprendida, lo que anhelamos».

59 El Republicano, p. 132, «... señores "no republicanos": la República ha de ser como ustedes la hagan». El jefe de la república, «Será quien ustedes quieran. Será el que la mayoría elija; es decir, el que elijan ustedes, puesto que ustedes han de ser muchos más que nosotros los republicanos de abolengo», ibíd., p. 98.

60 El Republicano, pp. 89-90. 


\section{... y en la esperanza, republicana y liberal}

¿Qué entendía Infante por una España republicana? Una comunidad política de ciudadanos capaces de abandonar el quietismo público sin renunciar al confort del hogar y de reconocer en la economía de mercado la fuente de la vida social y de las jerarquías sostenidas sobre el mérito. Las motivaciones personales, asegura, obran en pro del bien común. El Estado republicano de Infante, de manera diferente a lo que proponen sus correligionarios Marcelino Domingo o Manuel Azaña, o en la Argentina José Ingenieros ${ }^{61}$, es un Estado escaso: una organización política que asegura la soberanía política ante otras comunidades y una estructura administrativa que protege, junto a la infancia desatendida, la iniciativa particular. Infante rechaza tanto las actitudes rentistas - causa del atraso español - como la conversión del Estado en facilitador intervencionista para la emancipación de los humildes. La España republicana ha de reconocer, como la Argentina no atrapada por la demagogia populista, la propiedad como pilar del orden justo. Ello no quiere decir que, a partir de aquí, el marco republicano y liberal asuma la conveniencia de que el pueblo, en sus sectores más humildes, se proponga metas ambiciosas, adquiera conciencia de ciudadanía y se sienta comprometido de la iniciativa social junto a las élites republicanas. La República cambiará a España porque el republicanismo es exigente y trabajoso, «el republicanismo obliga a pensar mucho en los problemas de gobierno; obliga a formar ideas y exponerlas; obliga a discutirlas...»; así se crea una esfera pública y una ciudadanía. El mero cambio institucional obraría una transformación profunda. La república era el marco para que los ciudadanos pudiesen ampliar y preservar sus derechos básicos. El republicanismo militante, y el de Infante lo es, va más allá y se sitúa en un plano aristotélico: considera que el hombre es un animal político. La naturaleza plena del ser humano - la vida virtuosa - sólo se alcanza en una amplia y activa participación en la vida política. Por lo demás, la corresponsabilidad, conllevaría, en España, un genuino proceso de nacionalización.

El basamento de la coalición de viejos y nuevos republicanos, antes aludida, será un acuerdo tan de mínimos que solo excluirá a los monárquicos que se resistan a dejar de serlo. Lo que hay que procurar es el

${ }^{61}$ Halperin Donghi, 2015, p. 35. 
cambio institucional, alcanzar un «Gobierno responsable, viril, electivo, temporal». La virilidad, recurrente, se entiende por contraste a una modalidad institucional hereditaria que «cae frecuentemente en manos de niños, de mujeres extranjeras, de locos o de idiotas y siempre en manos de soberbios ${ }^{62}$. Infante participa de esa mezcla de valores (virtudes cívicas, modestia, responsabilidad frente a la ciudadanía y para con el bien común) y prejuicios (frente a lo femenino, ante la enfermedad) tan propia de la democracia hispana del momento.

Hay unos pocos puntos en los que Infante se permite saltarse la regla autoimpuesta de no anticipar soluciones cerradas. En lo relativo al jurado en la administración de justicia se muestra, como poco, receloso y proclive a eximir al ciudadano de obligaciones para con la misma. En materia militar aparece como un rupturista: clama por la desaparición de las capitanías generales y los gobiernos militares y entiende que el voluntariado ha de prevalecer sobre la conscripción obligatoria. Y, finalmente, respecto de la cuestión católica, y por pragmatismo - evitar pelearse con el clero - y por liberalismo - respeto a las conciencias y a las creencias advierte de los riesgos del anticlericalismo ${ }^{63}$.

Infante sostiene que el conjunto de los republicanos debería coincidir en el hecho que el poder ejecutivo fomente dos vectores de progreso y nacionalización: la escuela y el mercado. La enseñanza, en república, debería encaminar a los individuos hacia las actividades productivas y multiplicar «el número de los [españoles] dedicados a la industria». Hay algo en la idiosincrasia nacional que bloquea esa afición. La república debe modificarla desde la escuela y hacer de cada ciudadano alguien «más intensamente laborioso y más intensamente económico». La república debía usar la escuela para propiciar «un cambio completo en el concepto del ideal de vida»: trabajar y economizar ${ }^{64}$. La glosa del mercado, a su vez, es de lo más singular, por mantenerse en la lógica de la economía política en unos años en que la idea de la capacidad movilizadora de recursos y de potencialidades estatales en el desarrollo económico y la plena ocupación de las energías sociales se abría camino. A estos republicanos de la península difícilmente se les ocurre - excepto los que provienen del liberalismo dinástico - centrar las críticas al directorio en el sentido que impidió el funcionamiento normal de la ley de la oferta y la demanda y

\footnotetext{
${ }^{62}$ El Republicano, p. 7.

${ }^{63}$ El Republicano, pp. 119-121 y 134-135.

${ }^{64}$ El Republicano, pp. 163-168.
} 
bloqueó, con una agresiva política arancelaria, el comercio exterior ${ }^{65}$. Lo cierto es que Infante entendía la educación, y el libre mercado capitalista, la generalización de la propiedad de la tierra -incluyendo «la expropiación privada por causa de mejor aprovechamiento» ya que la tierra debe pertenecer a quien la trabaja, pero quien la trabaja la debe conservar como propiedad inalienable - y la rebaja de la presión fiscal y la oferta de trabajo que de él deriva, como motor de movilidad social, nacionalización y democratización ${ }^{66}$.

Ahondemos un poco en este punto dado que Infante presenta conectado con la migración y con lo que entiende han sido las bases del progreso argentino. El ideal de la plenitud republicana no es la pobreza sino el lujo honesto. Para ello el trabajo debe estar libre de toda tributación. El impuesto, si acaso y partiendo de la republicana «libertad del bolsillo», debe recaer en «los capitales que excedan de la cantidad cuya renta sea considerada suficiente para sostener una vida familiar de lujo honesto ${ }^{67}$. Si el Estado ha de ser una mera y tenue red de seguridad para cubrir aquello que privadamente no se alcance deja de tener sentido su volumen. Infante se muestra agresivo para con el empleo y la función pública: ejerce una competencia desleal en materia salarial para con los empresarios privados, detrae capital humano - de manera muy similar a como hace la Iglesia - y asegura un porvenir a individuos que resultarían más creativos en términos de riqueza nacional si empleasen su talento de manera competitiva en el mercado de trabajo y en la actividad empresarial. A todo ello, Infante se reconoce en minoría: «nosotros, los actuales republicanos somos pocos, y somos menos los republicanos no socialistas, los puramente republicanos» ${ }^{68}$.

Todo ello se fórmula, no se olvide, en un contexto de agitación social, tanto en España como en la Argentina y, como mínimo, desde 1919. Infante es consciente de ello y del terror que infunde, pero no altera su fondo liberal, en lo teórico, y pequeñoburgués, en lo proyectivo ${ }^{69}$. La cuestión social no se resolverá con el mero advenimiento republicano. El análisis de Infante tiene una raíz moral: es el egoísmo mal entendido

${ }^{65}$ El Republicano, p. 9.

${ }^{66}$ Romero, 2014, p. 149. El Republicano, p. 214: «PRODUCIR es primero; DISTRIBUIR viene después. He ahí toda la cuestión.». Ibíd., pp. 171-173.

67 El Republicano, pp. 178 y 182.

68 El Republicano, pp. 143-144, 183 y 186.

69 El Republicano, p. 210. 
lo que induce, con la huelga, a buscar con rapidez la satisfacción de los intereses propios, aún a costa de los de otros o de los del conjunto de la sociedad. Los problemas se desbordan por ausencia de códigos de conducta. Esta sólo mejorará mediante la lenta labor educativa. La erosión del egoísmo que, según Infante, mueve las acciones irreflexivas de los huelguistas sólo será posible mediante un perseverante ejercicio de aprendizaje de ciudadanía. Un aprendizaje que llevará, entre otras cosas, a asumir como un valor superior a defender y a respetar, el de la propiedad. Para el camino, para enfrentar estos ciclos, Infante no elude la posibilidad, antes bien la estimula, de un doble proceder: por un lado, crear una especie de cuarto poder, al que denomina Poder controlador, y que remite a los recientes institutos de reformas sociales, para que estudie «las condiciones en que estén las relaciones de cada capital y de cada trabajo»e insinúe «las modificaciones precisas cuando [aquellas] no estén siendo justas». Por el otro, algo muy similar a las guardias blancas que están apareciendo por todas partes: la organización de los hombres de buena voluntad para, en momentos de paroxismo huelguístico, dar salida a los servicios de emergencia, resistir a las presiones y exigencias que afecten a sectores como los transportes, los servicios de agua, luz, limpieza de las calles... y acudir a labores de $«$ suplencia en el trabajo» ${ }^{70}$.

Infante denuncia, de forma sistemática, cualquier exceso de intervencionismo. De hecho, casi cualquier intervencionismo es contemplado como un exceso. Lo hace porque los considera contraproducentes para el progreso, para el crecimiento material. Los impulsos legislativos, el animar al Estado a regular mediante leyes el libre juego del mercado, son una amenaza para el desarrollo y, normalmente, conducen a situaciones en las que los supuestos beneficiados resultarían los grandes perjudicados. Nuestro protagonista no elude, sin embargo, la importancia de la conquista de derechos políticos y su conexión con la reforma social: acudiendo al personalismo y entendiendo de forma positiva, sin los melindres de sus correligionarios en España aturdidos por la crítica regeneracionista al caciquismo, la operatividad de las formas democráticas de clien-

70 El Republicano, pp. 204-208. En el campo de las propuestas reformistas, Infante, de nuevo en liberal, previene contra el obligar por ley a favorecer «a las madres en estado interesante», dado que puede llevar al empresario a cerrar las puertas a toda mujer casada; a igualar salarios de hombres y mujeres por similar razón o a vetar el trabajo infantil cuando esto equivale, en ocasiones, a privar «de ganar el pan a niños que, indispensablemente, necesitan ganarlo». Ibíd., p. 215. 
telismo ${ }^{71}$. Infante sabe de la centralidad del sufragio en tanto asegura la dignidad del ciudadano humilde. El razonamiento es singular: el voto del pobre obliga a hacer modificaciones legislativas y, en absoluto menos importante, obliga, para con él, al «trato afable», a la «recomendación» y a los «pequeños servicios». Desde leer o escribir una carta a elaborar un informe, dar un consejo, facilitar alimentos o dinero o hacer ganar unos jornales en tiempos de crisis de trabajo ${ }^{72}$. Eso es lo que se consigue si el pobre es tan ciudadano como el potentado. Infante no plantea como esencial la participación política - el hacer uso real del voto- sino la posibilidad de la misma. En otras palabras: el derecho de practicarla, caso de desearse, de una forma instrumental.

¿Aleja esa lectura de los derechos políticos a Infante del republicanismo? En realidad, lo que hace es situarlo en unas coordenadas alejadas del populismo democrático de corte rousseauniano. El voto, de los varones mayores de edad o de la mujer que se halle al frente del hogar, es ni más ni menos que la palanca con la que alcanzar ese bienestar definido como el objetivo primero de los poderes públicos ${ }^{73}$.

\section{España y el mundo}

El compromiso republicano, en fin, se retoma porque en España hay una dictadura y porque el mundo está cambiando. El contexto es nuevo. Proliferan, sostiene Infante, las situaciones despóticas en España, «Italia y otros desdichados países». La comunidad internacional, a pesar de lo planteado tras la Gran Guerra, flaquea o se inhibe ante las tiranías emergentes. Bien al contrario, en el continente americano, dice Infante, los Estados Unidos habría procedido, en Centroamérica, al no reconocimiento de poderes constituidos por «medios extralegales». En Europa ello no ocurre y las potencias «siguen manteniendo relaciones con los salteadores de Poderes» ${ }^{74}$. Su reflexión, y su crítica, beben de y son herederos inconfundibles de la manera de entender las formas políticas y las relaciones internacionales en el contexto de preguerra mundial aderezada, eso sí,

71 Para los métodos tradicionales de clientelismo en la creación de un nuevo estilo político marcado por la tendencia a mantener las cosas en un plano personal, Horowitz, 2008.

72 El Republicano, p. 11.

73 Pettit, 1999, pp. 25 y 48-50.

74 El Republicano, p. 36. 
con una impregnación wilsoniana. Frente a las nuevas tiranías el republicanismo liberal no es para nada pacifista. Infante arguye que no son pocas las voces que reclaman la paz como un valor absoluto. Frente a ello, reclama el derecho. Y si no hay otro remedio, un intervencionismo liberal: la guerra para la conquista o la defensa del derecho agredido ${ }^{75}$. Como cuando Rosas procedió al apoderamiento de poderes, derechos y libertades... lo que procede contra el despotismo actual no es el diálogo sino la guerra.

Infante no hace uso de la categoría fascismo. No lo hace por anticomunismo. La paradoja es inequívocamente liberal. La gran amenaza civilizatoria es el comunismo, una variante de los credos religiosos que ataca la propiedad, base del orden social y del progreso. Es esa animadversión lo que aleja a Infante del antifascismo. No elude críticas a la dictadura italiana pero no acude a actos públicos antifascistas dado que suelen tomar la palabra militantes comunistas y algún «obrero orador» que ataca a la burguesía ante el entusiasmo de un auditorio que «se limita(n) a clamar y clamar sin razonar...». El anticomunismo le permite incidir de nuevo en su propuesta social «la mejor forma de combatirle es hacer individualistas por interés propio que se sumen a quienes somos individualistas por convicción pura» y el instrumento es la pequeña propiedad, hacer posible que las familias humildes constituyan «su hogar familiar en quinta propia y perpetua» ${ }^{76}$.

Está cambiando el mundo y el hispanoamericanismo se reformula. Un hispanoamericanismo que, antes del Directorio, ha reconciliado a emigrantes de toda condición. Reconciliación que con el golpe militar se quiebra pero que, en todo caso, se filtra en las consideraciones de Infante en El Republicano. Ha leído a Altamira y a Posada y comparte con ellos la idea de que la España que toca construir es la que quiere «vivir las formas nuevas y el espíritu pasado» ${ }^{77}$. Infante no podía escapar a la presuposición de la existencia de una identidad hispanoamericana común. Sin acariciar la idea de una unión política sus reflexiones traslucían la idea de que había un sustrato común a cultivar - «resintonizar» es el término usado por Altamira en diciembre de 1926 en el Centro de intercambio intelectual germanoespañol al dictar La finalidad de nuestro hispanoamericanismo y sus aplicaciones - entre las respectivas y diferenciadas naciones polí-

\footnotetext{
75 El Republicano, pp. 37-38.

76 El Republicano, pp. 219 y 175.

77 García Sebastiani, 2012,pp. 79-95; Altamira, 1917, p. 140.
} 
ticas. Tampoco podía escapar a una segunda premisa: el mantenerse alejado «de las utopías políticas por reacción contra los excesos retóricos del pasado y por su convencimiento de que las formas políticas no eran más que una consecuencia secundaria de la evolución de las estructuras mentales o psicológicas colectivas» ${ }^{78}$. Más allá de los proyectos y los conceptos, Infante participaba, y no era ello lo menos importante, de un estado de ánimo ante la época que atravesaban. Infante hubiese podido firmar las palabras inaugurales con las que Altamira reflexionaba, en 1929, sobre los contextos existentes:

«Todos producen en un ánimo como el mío la angustia del interrogante que pone en la inteligencia acostumbrada a estimar un orden de cosas como algo estable, fuertemente construido y con trayectoria clara e imposible de variar, el inesperado espectáculo de una situación en que asoman horizontes nuevos aun mal definidos, se quebrantan posiciones que parecían definitivamente adquiridas o se replantean en estado crítico cuestiones que se creyeron resueltas totalmente» ${ }^{79}$.

\section{Conclusión}

En la necrología que La Tierra, periódico rosarino, dedicó a Infante se afirma que este se había vinculado a la ciudad y al pueblo argentino, se había asimilado plenamente porque «...es la característica dominante de todo hombre superior (que) sabe[r] advertir dónde se encuentra una posibilidad de superación». Infante se asimiló en una época en la que el liberalismo derivaba hacia la democracia, en un contexto en el cual, para superarse, se hizo argentino con el objetivo de devenir ciudadano pleno e incidir, desde esa posición, en la creación de condiciones similares en su patria primera ${ }^{80}$. El proyecto de Infante apenas fue escuchado. Seguro que por el aislamiento, que no por la falta de prestigio del rosarino, en el seno del movimiento republicano de los españoles en Argentina. Un movimiento que asistirá asombrado a la crisis de lo construido entre 1912 y 1916 como consecuencia del desgaste de los materiales políticos y de una crisis que facilitaba la apertura de un momento, en el ámbito de las

\footnotetext{
78 Niño, 1993, p. 20, citando a Altamira.

79 Altamira, 1929, p. 9.

80 El Republicano, p. 399.
} 
ideas políticas, inequívocamente maquiaveliano - divergiendo de lo que se apuntaba entre 1929 y 1930, en España. Tampoco fue escuchado por la más elemental de las razones: fue de aquellos republicanos históricos que, por poco, no llegaron a ver en vida la llegada del 14 de abril. Y, finalmente, porque en España la república abrió un proceso de «reformismo masivo» alejado de la lectura liberal de Infante.

La premura, la improvisación en los planes y en los instrumentos, y la sucesión de actuaciones de escasa coordinación serían rasgos que, en base a testimonios periodísticos de la época, Julio Aróstegui atribuyó a esos tiempos. Esa urgencia chocaba con la filosofía política que, en su doble condición de demócrata español y de ciudadano argentino, Infante sostuvo en las páginas de El Republicano. Él partía de un principio de prudencia de clara raíz liberal y burguesa, defendía un republicanismo liberal y una democracia reformista que procurase la resolución ambiciosa y equilibrada, a un tiempo, de los grandes problemas nacionales $^{81}$.:

«Hemos aprendido, entre otras cosas, que no se deben destapar a un tiempo todos los avisperos; que no se puede descender de las montañas o salir de los barrancos de un salto; que hay que ir paso a paso, y afianzando bien los pies, y no soltando una mano hasta tener la otra bien asegurada» ${ }^{82}$.

Entre 1930 y 1931 , sus dos patrias ensayarían caminos distintos a los que él había propuesto. En El Republicano, Infante planteó, en solitario, un republicanismo que entendía la libertad no como una dotación pre política del individuo sino como un estado que arrancaba de la sujeción a la Ley. La libertad política era una condición colectiva, nacional, desde el momento en la que se aseguraba al individuo la posibilidad (real) de construir su propio bien. Es una filosofía política que se forja en la década de 1880, se explicita en la de los noventa, se va perfilando en las décadas siguientes y, cuando en 1925 decide enfrentarse a una Dictadura a la que atribuía los dicterios recogidos en las páginas precedentes, llama a sus compatriotas a la acción - al cometido propio del ciudadano-, para sentar las bases de un orden que permita la plenitud individual. Este seguirá siendo, como cuando emigra, su objetivo último. Los principios ha-

\footnotetext{
81 Aróstegui, 2006, p. 56.

82 El Republicano, p. 87.
} 
cia los que oscila su liberalismo - valor preferente de la autonomía y los derechos individuales - los creía perfectamente compatibles con aquellos hacia los que gravita su republicanismo - virtud cívica y responsabilidad para con lo público y el bien común.

La admonición se produce en un momento en el cual incluso los elementos que procedentes del campo monárquico y conservador que se suman a la ola republicana aceptan que la liquidación de la monarquía supondrá en España una revolución política orientada a satisfacer con cierta prontitud las expectativas de justicia social que se han ido acumulando. Frente a ello la recomendación de Infante es concluyente. El republicano debe aspirar a una sola cosa: lograr que el jefe del Estado sea electivo, temporal y responsable. Propugna, pues, un cambio institucional que no comporte, a priori, mayores ambiciones adosadas. En ese cambio institucional se halla la sustancia tanto como la condición de posibilidad: los republicanos deben comprender que lo esencial es la forma del Gobierno, no las actuaciones que a él puedan asociarse. Las formas, sostiene, no son accidentales. Por el contrario, hacen posible e impulsan, como ocurre en Argentina desde 1912, como pasa en Francia desde mediados de la década de 1870, todo tipo de posibilidades. Pero no son estas las que deben ponerse por delante. Si la monarquía es la entronización del poder a ciegas, la república es la entronización de una ciudadanía con los ojos bien abiertos. Esa es, desde la Argentina, la sustancia del cambio propuesto a España.

\section{Fuentes}

El REPUBLICANO, Rosario de Santa Fe, «Colaboración del Doctor J. Daniel Infante (Corona fúnebre)». Librería y Editorial La Facultad-Juan Roldán y C. ${ }^{\text {a }, \text { Buenos Aires } 1932 .}$

ALTAMIRA, Rafael, España y el programa americanista, Ed. América, Madrid, 1917.

ALTAMIRA, R., Últimos escritos americanistas, Compañía Ibero-Americana de Publicaciones, Madrid, 1929.

AZCÁRATE, Gumersindo de, El régimen parlamentario en la práctica, Madrid, Sobrinos de los Sucesores de Minuesa de los Ríos, Madrid, 1931, edición homenaje.

BLASCO IBÁÑEZ, Vicente, Argentina y sus grandezas, La Editorial Española Americana, Madrid, 1910. 
Dolor de dictadura, anhelo de república. El caso del emigrante J. D. Infante y El Republicano

BLASCO IBÁÑEZ, V., Alphonse XIII démasqué: la terreur militariste en Espagne, París, Flammarion, 1924.

BLASCO IBÁÑEZ, V., París: impresiones de un emigrado, introducción y notas de Libertad Blasco-Ibáñez, México, Prometeo, 1943, 2. a ed.

INFANTE, J. Daniel, Estudiemos política. Monarquía y República, La Industrial, Rosario de Santa Fe, 1893.

INFANTE, J. D., Unitarismo y federación, Rosario de Santa Fe, Imp. Villalón Hnos., Rosario de Santa Fe, 1894.

INFANTE, J. D., La revolución española, Imp. La Capital, Rosario, 1908.

INFANTE, J. D., Insinuaciones. Serie de conferencias didácticas, Rosario, Imprenta Inglesa, Rosario, 1916.

INFANTE, J.D., i¡Por España!! Reflexiones de un expatriado, Madrid, Editorial Reus, 1920.

\section{Bibliografía}

ARÓSTEGUI, Julio (ed.), La República de los trabajadores. La Segunda República y el mundo del trabajo, Madrid, Fundación Francisco Largo Caballero, 2006.

BACHERO BACHERO, Juan Luis, La neutralización del adversario político. La deportación en la España del siglo XIX, Universitat Jaume I, Castelló, 2017, tesis doctoral DOI http://dx.doi.org/10.6035/14013.2017.12057

BERNASCONI, Alicia y FRID, Carina (ed.), De Europa a las Américas. Dirigentes y liderazgos (1880-1960), Ed. Biblos, Buenos Aires, 2006.

BERTONI Lilia Ana, Patriotas, cosmopolitas y nacionalistas. La construcción de la nacionalidad argentina a finales del siglo XIX, FCE, Buenos Aires, 2001.

BLANCO RODRIGUEZ, Juan Andrés, «Asociaciones castellanas y leonesas en América», en BLANCO, J.A. (ed.), El asociacionismo en la emigración española a América, UNED Zamora/Junta Castilla y León, Salamanca, 2008, pp. 525-560.

BONAUDO, Marta «Entre la movilización y los partidos. Continuidades y rupturas en la crítica coyuntura santafesina de 1912», en MELÓN y PASTORIZA (comp.), Los caminos de la democracia. Alternativas y prácticas políticas, UNMar del Plata-Biblos, Buenos Aires, 1996, pp. 77-100.

BONAUDO, M. (dir.), Imaginarios y prácticas de un orden burgués, Rosario 1850-1930: Los actores entre las palabras y las cosas, Prohistoria, Rosario, 2005.

CAGIAO, Pilar, «El americanismo español en 1912: agenda, proyectos y preocupaciones», en XIX Jornadas de la Muy Noble y Leal Ciudad de Ayamonte, Ayuntamiento de Ayamonte, Huelva, 2015, pp. 86-97. 
CASTRO, Martín O., El ocaso de la república oligárquica: poder, política y reforma electoral, 1898-1912, Edhasa, Buenos Aires, 2012.

CASTRO ALFÍN, Demetrio (coord.), Líderes para el pueblo republicano. Liderazgo político en el republicanismo español del siglo XIX, Universidad Pública de Navarra, Pamplona, 2015.

CORTÉS CONDE, Roberto, El progreso argentino, 1880-1914, Sudamericana, Buenos Aires, 1979.

DA ORDEN, María Liliana, «Liderazgo étnico y redes sociales: una aproximación a la participación política de los españoles en la Argentina, 18801912», en FERNÁNDEZ, A.E. y MOYA, J.C. (eds.), La inmigración española en la Argentina, Buenos Aires, Biblos, 1999, pp.167-193.

DALLA CORTE, Gabriela, Lealtades firmes. Redes de sociabilidad y empresas. La «Carlos Casado SA», entre la Argentina y el Chaco Paraguayo (18601940), CSIC, Barcelona, 2009.

DELGADO GÓMEZ-ESCALONILLA, Lorenzo, «La política latinoamericana de España en el siglo XX», Ayer, 49, 2003, pp. 121-160.

DEVOTO, Fernando, Historia de la inmigración en la Argentina, Sudamericana, Buenos Aires, 2003.

DEVOTO, Fernando, «Introducción», a BERNASCONI, Alicia y FRID, Carina (eds.), De Europa a las Américas. Dirigentes y liderazgos (1880-1960), Biblos, Buenos Aires, 2006, pp. 9-14.

DUARTE, Ángel, «La Liga Republicana Española en la Argentina: política y sociabilidad (1903-1907)», Anuario IEHS, 8, 1993, pp. 307-344.

DUARTE, Á., La república del emigrante. La cultura política de los españoles en la Argentina (1875-1910), Milenio, Lleida, 1998.

DUARTE, Ángel, «J. Daniel Infante: el castellano diáfano, el republicano perplejo», en GARCIA SEBASTIANI, Patriotas entre naciones, 2010, pp. 58-81.

FERNÁNDEZ, Alejandro E., «Patria y cultura. Aspectos de la acción de la elite española en Buenos Aires, 1890-1920», Estudios Migratorios Latinoamericanos, 6-7 (1987), pp. 291-307.

FERNÁNDEZ, Alejandro E., «Prèdiques de Germanor. Las asociaciones catalanas de Buenos Aires y sus prácticas institucionales (1850-1940)», Historia Social, 70, 2011, pp. 63-80.

GALLO, Ezequiel, La pampa gringa: la colonización agrícola en Santa Fe (1870-1895), Sudamericana, Buenos Aires, 1984.

GARABEDIAN, Marcelo Hugo, La construcción de un colectivo español. El Correo Español de Buenos Aires (1872-1905), tesis de doctorado, Universidad Torcuato Di Tella, Buenos Aires, 2017.

GARCÍA SEBASTIANI, Marcela, «Crear identidades y proyectar políticas de España en la Argentina en tiempos de transformación del liberalismo. El Diario Español de Buenos Aires (1905-1912)», Estudios Migratorios Latinoamericanos, 55, 2004, pp. 525-554. 
Dolor de dictadura, anhelo de república. El caso del emigrante J. D. Infante y El Republicano

GARCÍA SEBASTIANI, M., «Influencia y proyección del republicanismo de Nicolás Salmerón en la Argentina», Jarbuch für Geschichte Lateinamerikas, 43, 2006, pp. 275-300.

GARCIA SEBASTIANI, M., «Interlocutores y escenarios del liberalismo reformista español en la Argentina» en GARCIA SEBASTIANI, M. y DEL REY REGUILLO, Fernando (coord..), Los desafios de la libertad. Transformación y crisis del liberalismo en Europa y América Latina, Biblioteca Nueva, Madrid, 2008, pp. 340-370.

GARCIA SEBASTIANI, M. (dir.), Patriotas entre naciones. Élites emigrantes españolas en Argentina (1870-1940), Editorial Complutense, Madrid, 2010.

GARCÍA SEBASTIANI, M., «Emigración, nacionalismo y conmemoraciones», en MORENO LUZÓN, J. y GUTIÉRREZ VIÑUALES, R. (eds.), Memorias de la independencia. España, Argentina y México en el primer centenario (1908-1910-1912), SEEC, Madrid, 2012, pp. 79-95.

GARCÍA SEBASTIANI, Marcela, «España fuera de España. El patriotismo español en la emigración argentina: una aproximación», Hispania, 244, 2013, pp. 469-500.

GARCÍA SEBASTIANI, Marcela y NÚÑEZ SEIXAS, Xosé Manoel (eds.), $\mathrm{Ha}$ cer patria lejos de casa. Nacionalismo español, migración y exilio en Europa y América (1870-1975), PUZ, Zaragoza, 2020.

GUERRA, François-Xavier, «Las metamorfosis de la representación en el siglo XIX», en COUFFIGNAL, Georges (comp.), Democracias posibles. El desafío latinoamericano, FCE, Buenos Aires, 1994, pp. 39-68.

HALPERIN DONGHI, Tulio, La Argentina y la tormenta del mundo. Ideas e ideologías entre 1930 y 1945, Siglo XXI editores, Buenos Aires, 2013, 2. edición.

HALPERIN DONGHI, T., Las tormentas del mundo en el Río de la Plata. Cómo pensaron su época los intelectuales del siglo XX, Siglo XXI editores, Buenos Aires, 2015.

HIGUERAS CASTAÑEDA, Eduardo, Con los Borbones, jamás. Biografía de Manuel Ruiz Zorrilla (1833-1895), Marcial Pons, Madrid, 2016.

HOROWITZ, John, Argentina's Radical Party and Popular Mobilization, 19161930, The Pennsylvania University Press, 2008, ebook.

JAÉN MORENTE, Antonio, La lección de América, Sucesores de Rivadeneyra, Madrid, 1934. Edición facsímil, Universidad de Córdoba, Córdoba, 2005.

KARUSH, M. B., «Workers, Citizens and the Argentine Nation: Party Politics and the Working Class in Rosario, 1912-1913», Journal of Latin American Studies 31:3, 1999, pp. 589-616.

MARKOFF, John, Olas de democracia. Movimientos sociales y cambio político, 2. ${ }^{\text {a }}$ edición, Comares, Granada, 2018.

MARTIRÉN, Juan Luis, «Expansión y modernización agraria. La economía santafesina durante la segunda mitad del siglo XIX, Avances del Cesor, 11, 2014, pp. 135-154. 
MAURO, Diego A., «Liberalismo, democracia y catolicismo en Argentina. La reforma constitucional de 1921 y las identidades políticas. Santa Fe, 19201923», Boletín Americanista, 57, 2007, pp. 87-106.

MAURO, Diego A., «Procesos de laicización en Santa Fe (Argentina): 18601900. Consideraciones sobre la Argentina "liberal y laica"», Revista de Indias, v. LXXIV, 2. 261, 2014, pp. 539-560.

MIRAGAYA, Eduardo y SOLANES, Francisco, Los españoles en Rosario de Santa Fe. Su influencia en el progreso de la ciudad, La Cervantina, Rosario, 1934.

MORENO LUZÓN, Javier, «Reconquistar América para regenerar España. Nacionalismo español y centenario de las independencias en 1910-1911», Historia Mexicana, 237, 2010, pp. 561-640.

MOYA, José C., Cousins and Strangers. Spanish Immigrants in Buenos Aires, 1850-1930, University of California Press, Berkeley, 1998.

NIÑO RODRÍGUEZ, Antonio, «Hispanoamericanismo, regeneración y defensa del prestigio nacional (1898-1931)», en PÉREZ HERRERO, Pedro y TABANERA, Nuria (coord.), España/América Latina: un siglo de políticas culturales, AIETI/Síntesis OEI, Madrid, 1993, pp. 15-48.

NÚÑEZ SEIXAS, Xosé Manoel, «Nota sobre Los españoles en Rosario (1934): Una vindicación republicana de la inmigración española en la Argentina», Revista de Indias, v. LXXIII, n. 259, 2013, pp. 857-874.

NÚÑEZ SEIXAS, X. M., «Migrant associations: the Spanish transatlantic experience», Social History, 41-2, 2016, pp. 136-154.

NÚÑEZ SEIXAS, X. M., «¿Negar o reescribir la Hispanidad? Los nacionalismos subestatales ibéricos y América Latina, 1898-1936», Historia Mexicana, 265, 2017, pp. 401-458.

NUÑEZ SEIXAS, X. M., «Galician Immigrant Societies in Cuba: Local Identity, Diaspora Politics and Atlantic Mobilization (1870-1940), en Journal of Social History, 52-3, 2019, pp. 705-730.

NÚÑEZ SEIXAS, X. M., Patriotas transnacionales. Estudios sobre nacionalismos y transferencias culturales en la Europa del siglo XX, Cátedra, Madrid, 2019.

ORTUÑO MARTÍNEZ, Bárbara, «Del Casino al Centro: el exilio republicano y el asociacionismo español en América», Historia Social, 70, 2011, pp. 155173.

ORTUÑO MARTÍNEZ, Bárbara, Hacia el hondo bajo fondo... Inmigrantes y exiliados en Buenos Aires tras la guerra civil española, Biblioteca Nueva, Madrid, 2018.

PASQUALI, Patricia S., J. Daniel Infante, Editorial Municipal, Rosario, 1996.

PETTIT, Philip, Republicanismo. Una teoría sobre la libertad y el gobierno, Paidós, Barcelona, 1999. 
Dolor de dictadura, anhelo de república. El caso del emigrante J. D. Infante y El Republicano

PRADO, Gustavo H., «La estrategia americanista de Rafael Altamira tras la derrota del proyecto ovetense (1910-1936). Entre el lobby parlamentario y el refugio académico», en DALLA CORTE CABALLERO, G., LLUS I VIDAL-FOLCH, A., y CAMPS I PLANA, F. (coord.), De las independencias al Bicentenario, Casa de América, Barcelona, 2006, pp. 71-88,

PRADO, Gustavo H., Rafael Altamira en América (1909-1910). Historia e historiografía del proyecto americanista de la Universidad de Oviedo, CSIC, Madrid, 2008.

ROCK, David, El radicalismo argentino, 1890-1930, Amorrortu, Buenos Aires, 1997, 2. ${ }^{\text {a }}$ reimp.

ROMERO, Ana L., «La política del patriotismo. La conformación de la Asociación Patriótica Española (1896-1898), Estudios Migratorios Latinoamericanos, 64, 2007, pp. 457-485.

ROMERO, José Luis, La experiencia argentina y otros ensayos, Ed. de Belgrano, Buenos Aires, 1980.

ROMERO, Luis Alberto, Sociedad democrática y política democrática en la Argentina del siglo XX, Universidad Nacional de Quilmes, Bernal, 2004.

ROMERO, Luis Alberto, «Sociedad democrática y política nacional y popular: la Argentina en la primera mitad del siglo XX», Estudios Sociales 46, 2014, pp. 145-170.

SÁBATO, Hilda, La política en las calles. Entre el voto y la movilización. Buenos Aires, 1862-1880, Sudamericana, Buenos Aires, 1998.

SÁNCHEZ, Santiago Javier, «La intendencia de Daniel Infante en Rosario (19121913): las paradojas de un socialista español», Historia Regional 23, 2005 , pp. 91-102.

SEPÚLVEDA, Isidro, El sueño de la Madre Patria. Hispanoamericanismo y nacionalismo, Fundación Carolina/CEHeI/Marcial Pons, Madrid, 2005.

SERRANO BLANCO, Laura, «El reformismo social republicano en el pensamiento de Ricardo Macías Picavea», Investigaciones Históricas 19, 1999, pp. 179-196.

SIERRA, María, «Enemigos internos. Inclusión y exclusión en la cultura política liberal», en PRO, J., SIERRA, M. y MAURO, D.A., Desde la Historia. Homenaje a Marta Bonaudo, Imago Mundi, Buenos Aires, 2014, pp. 73-90.

SMITH, Peter H., Democracy in Latin America. Political Change in Comparative Perspective, Oxford University Press, Nueva York, 2005.

VIDELA, Oscar R. y ZANELLA, Eduardo (comp.), Historia y Política: Estudios sobre Ricardo Caballero, Imago Mundi, Buenos Aires, 2004.

ZIMMERMAN, Eduardo, «Los intelectuales, las ciencias sociales y el reformismo liberal: Argentina, 1890-1916», Desarrollo Económico, 124, 1992 , pp. 545-564.

ZIMMERMAN, Eduardo, «Circulación de saberes jurídicos: el derecho administrativo y el estado en la Argentina, 1880-1930», texto en Academia.edu, 
traducción de «Circulation des savoirs juridiques: le droit administratif et l'Etat en Argentine, 1880-1930», en PÉREZ, Liliana et GONZÁLEZ BERNALDO, Pilar (sous la dir.), Les savoirs-mondes. Mobilités et circulation des savoirs depuis le Moyen Âge, Rennes, Presses Universitaires de Rennes, 2015, pp. 421-437.

\section{Financiación}

Este trabajo forma parte de los resultados del proyecto «La patria hispana, la raza latina. Intelectuales, identidades colectivas y proyectos políticos entre España, Italia y Argentina (1880-1945)», financiado por el Ministerio de Industria, Economía y Competitividad (HAR2016-75324-P).

\section{Datos del autor}

Ángel Duarte Montserrat es Catedrático de Historia Contemporánea. En la actualidad se halla trabajando en la Universidad de Córdoba en comisión de servicios. Entre sus líneas de investigación figuran las relativas al estudio de la cultura republicana en la España contemporánea, así como el cultivo de las identidades políticas entre los emigrados españoles al Río de la Plata en los decenios a caballo entre los siglos XIX y XX. Su libro más reciente es El republicanismo. Una pasión política (Cátedra, 2013). Ha publicado artículos de investigación, entre otras, en Ayer, Historia Contemporánea, Historia y Política, Historia Social, Anuario del IEHS, Memoria e Ricerca. Rivista di Storia Contemporanea, Le Mouvement Social. Forma parte de equipo de investigadores del Proyecto "La patria hispana, la raza latina. Intelectuales, identidades colectivas y proyectos políticos entre España, Italia y Argentina (1880-1945)» (HAR2016-75324-P). 